\title{
Pain Perception and Rate of Canine Retraction Through Self- Ligating Brackets and Conventional Elastomeric Ligation System: A Split Mouth Study
}

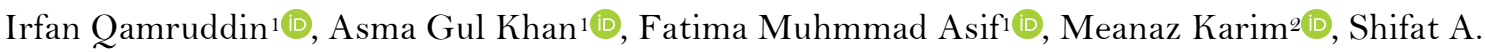

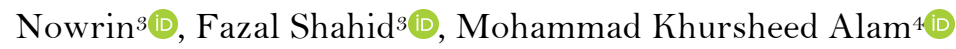

${ }^{1}$ Department of Orthodontics, Sindh Institute of Oral Health Science, Jinnah Sindh Medical University, Karachi, Pakistan.

${ }^{2}$ Prosthodontic Unit, School of Dental Science, Universiti Sains Malaysia, Kelantan, Malaysia.

${ }^{3}$ Orthodontic Unit, School of Dental Science, Universiti Sains Malaysia, Kelantan, Malaysia.

${ }^{4}$ Orthodontic Department, College of Dentistry, Jouf University, Sakaka, Kingdom of Saudi Arabia.

Author to whom correspondence should be addressed: Mohammad Khursheed Alam, Associate Professor, Orthodontic Department, College of Dentistry, Jouf University, Sakaka, KSA. Phone: +966535602339. E-mail: dralam@gmail.com.

Academic Editors: Alessandro Leite Cavalcanti and Wilton Wilney Nascimento Padilha

Received: 22 August 2019 / Accepted: 19 January 2020 / Published: 13 February 2020

How to cite this article: Qamruddin I, Khan AG, Asif FM, Karim M, Nowrin SA, Shahid F, Alam MK. Pain perception and rate of canine retraction through self-ligating brackets and conventional elastomeric ligation system: a split mouth study. Pesqui Bras Odontopediatria Clín Integr. 2020; 20:e5 147. https://doi.org/10.1590/pboci.2020.034

\begin{abstract}
Objective: To evaluate the rate of tooth movement and the pain perception via self-ligating (SL) and conventional elastomeric ligation brackets (CB) system. Material and Methods: This study has been conducted at the Orthodontic Department of Baqai Dental College, Baqai Medical University. The sample size of this study comprised 40 patients, falling between the age of 12-30 years without any sex discrimination. Shapiro-Wilk was used to check the distribution of data. Non-parametric Mann Whitney U test was applied to evaluate the pain associated with SL and CB brackets system. To analysis the canine retraction Wilcoxon test was applied for the comparison of CB and SL brackets system. For all statistical analyses, the p-value of $<0.05$ was considered significant. Results: Pain level associated with retraction via $\mathrm{CB}$ and SL shows significant differences. However, the rate of canine retraction via CB and SL shows no significant differences at stages To-T1 and T1-T2. However, stage T2-T3 shows a significant difference. Conclusion: As pain during orthodontic treatment is mostly associated with the level of compression of the periodontal ligament, it may be hypothesized that lower frictional forces generate less compression of the periodontal ligament and blood vessels, and so alter the type of pain experienced.
\end{abstract}

Keywords: Orthodontics; Tooth Movement Techniques; Orthodontic Brackets. 


\section{Introduction}

Orthodontic treatment can improve dentofacial esthetics as well as masticatory function, but treatment with fixed appliances can be associated with few complications and inherent risks [1,2]. Enamel decalcification, pain and masticatory discomfort, root resorption, gingivitis, and gingival hyperplasia are amongst the commonest complications in orthodontics [1]. Most of the adverse effects are either due to heavy forces applied on the teeth to achieve desirable movements or difficulty in maintaining oral hygiene and bacterial colonization around the brackets [3].

A light force is ideal for achieving all kinds of tooth movements [2], but more than $50 \mathrm{~g}$ of orthodontic force is wasted in overcoming the static friction produced by elastomeric ligatures [4]. Therefore much heavier than optimum force is needed to achieve even the simplest movement, which may cause more pain, discomfort, root resorption, delayed movement and even anchorage loss [5]. Orthodontic treatment is not only considered to be a painful procedure but also anticipated to be a painful treatment by patients even before the beginning of treatment [6,7]. From a patient's perspective, pain is the worst aspect and main cause of discontinuation of orthodontic treatment [8,9].

On the other hand, conventional elastomeric modules also accumulate plaque, which makes the tooth more prone to develop a carious lesion and, more commonly, gingival inflammation [7]. Self-ligating brackets are ligature-less brackets and have an inbuilt mechanism to secure and release the arch wire. Irrespective of the type, the self-ligation system in general claim to be more efficient as it reduces the adverse effects which are associated with elastomeric modules in the conventional ligating system. Therefore, the purpose of this research is to evaluate the rate of tooth movement and the pain perception via self-ligating and conventional elastomeric ligation brackets system.

\section{Material and Methods}

Study Design and Sample

This study has been conducted at the Orthodontic Department of Baqai Dental College, Baqai Medical University. The sample size of this study comprised of 40 patients, falling between the age of 12-30 years without any sex discrimination. Patients who required maxillary or mandibular canine retraction in the first premolar extraction site were included randomly in the current study from OPD, regardless of Class I, Class II, and Class III malocclusion. However, patients with cleft lip-palate and syndromic patients were excluded.

After informing and having a consent form signed by patients or their guardians, banding and bonding procedure were carried out. Edgewise brackets with MBT prescription (0.022x0.028-inch slot Gemini, 3M Unitek) were bonded in three randomly selected quadrants in all the patients while self-ligating brackets were bonded in the remaining quadrant. For initial alignment and leveling, 0.014 NiTi wire was inserted, followed by 0.016, 0.017x0.025, 0.019x0.025 Niti and 0.019x0.025 SS at one-month interval.

\section{Measurement of Pain Level Associated with Retraction}

A week after extraction of premolars, retraction of canines was carried out on 19x25 SS wire, using elastomeric chain exerting $150 \mathrm{~g}$ of force [10]. Force level was measured using Dentus gauge. To minimize the friction, the elastomeric chain was attached to the hooks of canine brackets bilaterally throughout canine retraction. To evaluate the pain associated with both types of brackets, a Performa was given to patients. To evaluate the pain perception associated with CB and SL brackets system, a numerical rating scale (NRS) was used [11]. An 11-point NRS was used to formulate a questionnaire to record the pain intensity associated with 
canine retraction, where o indicated "no pain" and 10 indicated "an intolerable pain”. Questionnaires were given to all the patients to fill out at home and bring back on their next visit. Patients were told to record their pain intensity 4 hours after the procedure and then after every 24 hours for the next seven days. They were also advised to record the most severe pain they experienced in the past 24 hours, so that the intense episode was not missed even if the pain subsided at the time of recording.

Reminders to fill the questionnaire were also given to the patients daily by phone calls. Patients were also discouraged to take analgesics, if taken in case of severe pain then they were advised to note it. Patients were called for their regular orthodontic follow-up visits every three weeks. The same procedure was repeated for three consecutive visits i.e.; T1, T2 and T3.

Rate of Movement Associated with Bracket Types

To evaluate the rate of movement digital caliper was used to measure the distance between the dental midline and the mesial surface of canine intraorally. Initial measurement was made before the start of retraction (To), and was repeated at 4 weeks (T1), 8 weeks (T2) and 12 weeks (T3) intervals. The amount of retraction was calculated by getting the difference of measurements i.e. To-T1, T1-T2 and T2-T3. To-T3 was taken as a difference in the rate of retractions between conventional and self-ligating brackets (Figure 1).

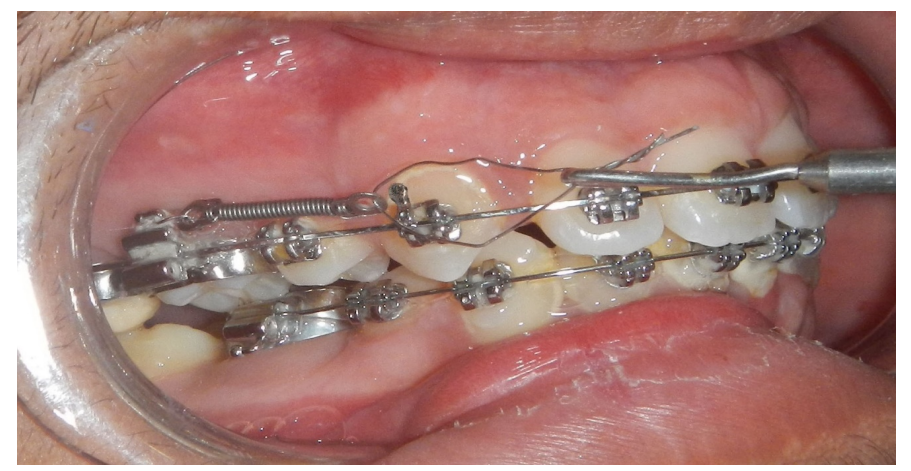

Figure 1. Canine retraction

Statistical Analysis

SPSS version 22.0 was used to record and analyze the data. Shapiro-Wilk was used to check the distribution of data. Since data were not normally distributed, a non-parametric Mann Whitney U test was applied to evaluate the pain associated with SL and CB brackets system. To analysis the canine retraction Wilcoxon test was applied for the comparison of CB and SL brackets system. For all statistical analyses, the pvalue of $<0.05$ was considered significant.

\section{Results}

Tables 1, 2 and 3 show significant differences in the rate of pain associated with CB and SL ligating system. Moreover, the self-ligating brackets were less painful.

Table 1. Comparison of pain between the smart clip and conventional bracket side at T1.

\begin{tabular}{cccc}
\hline Days & $\begin{array}{c}\text { Smart Clip } \\
\text { (Mean Ranking) }\end{array}$ & $\begin{array}{c}\text { Conventional Bracket } \\
\text { (Mean Ranking) }\end{array}$ & p-value \\
\hline 1 & 26.90 & 54.10 & $0.0001^{*}$ \\
2 & 27.50 & 53.50 & $0.0001^{*}$
\end{tabular}




\begin{tabular}{cccc}
3 & 26.50 & 54.50 & $0.0001^{*}$ \\
4 & 26.50 & 54.50 & $0.0001^{*}$ \\
5 & 25.30 & 55.70 & $0.0001^{*}$ \\
6 & 28.90 & 52.10 & $0.0001^{*}$ \\
7 & 32.50 & 48.50 & $0.0001^{*}$ \\
\hline *Significant at p<0.05 (Mann Whitney U test).
\end{tabular}

Table 2. Comparison of pain between the smart clip and conventional bracket side at T2.

\begin{tabular}{cccc}
\hline Days & $\begin{array}{c}\text { Smart Clip } \\
\text { (Mean Ranking) }\end{array}$ & $\begin{array}{c}\text { Conventional Bracket } \\
\text { (Mean Ranking) }\end{array}$ & p-value \\
\hline 1 & 27.45 & 53.55 & $0.0001^{*}$ \\
2 & 26.00 & 55.00 & $0.0001^{*}$ \\
3 & 26.39 & 54.61 & $0.0001^{*}$ \\
4 & 24.74 & 56.26 & $0.0001^{*}$ \\
5 & 23.63 & 57.38 & $0.0001^{*}$ \\
6 & 23.86 & 57.14 & $0.0001^{*}$ \\
7 & 28.50 & 52.50 & $0.0001^{*}$ \\
\hline *Significant at $\mathrm{p}<0.05$ (Mann Whitney U test).
\end{tabular}

Table 3. Comparison of pain between the smart clip and conventional bracket side at T3.

\begin{tabular}{cccc}
\hline Days & $\begin{array}{c}\text { Smart Clip } \\
\text { (Mean Ranking) }\end{array}$ & $\begin{array}{c}\text { Conventional Bracket } \\
\text { (Mean Ranking) }\end{array}$ & p-value \\
\hline 1 & 27.95 & 53.05 & $0.0001^{*}$ \\
2 & 25.91 & 55.09 & $0.0001^{*}$ \\
3 & 25.18 & 55.83 & $0.0001^{*}$ \\
4 & 24.68 & 56.33 & $0.0001^{*}$ \\
5 & 23.96 & 57.04 & $0.0001^{*}$ \\
6 & 24.06 & 56.94 & $0.0001^{*}$ \\
7 & 28.73 & 52.28 & $0.0001^{*}$ \\
\hline
\end{tabular}

*Significant at $\mathrm{p}<0.05$ (Mann Whitney U test).

Table 4 shows no significant differences in the rate of canine retraction in stage To-T1 and T1-T2. However, stage T2-T3 shows a significant difference in the rate of canine retraction associated with CB and SL ligating system.

Table 4. Comparison of canine retraction in CB and SL group.

\begin{tabular}{ccccccc}
\hline Measurements & CB & Sean & SD & Mean & SD & p-value \\
\hline To-T1 & 0.89 & 0.31 & 0.82 & 0.21 & 0.168 \\
T1-T2 & 0.82 & 0.37 & 0.86 & 0.33 & 0.491 \\
T2-T3 & 0.93 & 0.33 & 0.82 & 0.24 & $0.020^{*}$ \\
\hline
\end{tabular}

CB: Conventional Bracket; SL: Self-Ligating; SD: Standard Deviation; *Significant difference (Wilcoxon test).

\section{Discussion}

The study was carried out to confirm our hypothesis that the self-ligating bracket system is less painful as compared to the old conventional system. Pain may vary from patient to patient and their threshold for bearing pain. But our study confirms the hypothesis that due to less friction produced by self-ligating brackets, the patient is more comfortable. However, in the conventional system, the patient tends to face more discomfort and for a longer time span.

This study analyzed perceived discomfort after the initial placement of two different pre-adjusted fixed appliance systems. The discomfort was measured using an NRS, which is one of the most commonly used tools in the measurement of perceived discomfort during orthodontic treatment. This system is readily understood 
by most patients and is reliable, demonstrating good sensitivity between small changes and good reproducibility [9]. Typically, appliance-related pain is believed to peak at 24 hours to 3 days following manipulation of the appliance before reducing to near-baseline levels at 5 to 6 days postoperatively [12]. The findings seem to indicate that, in general, regardless of the type of appliance used (conventional or selfligating), pain is higher during the first two or three days after appliance activation. These results are consistent with those of several investigations that evaluated pain associated with orthodontic treatment [3].

During orthodontic treatment patients experience two types of discomfort: pain due to heavy forces applied to the tooth during chair side manipulation of wires and delayed type of pain after activation of any appliance as a result of orthodontic force [13]. The researcher found in a split-mouth study that self-ligating brackets are less painful while removal and insertion of heavy rectangular arch wires compared to conventional brackets because heavy forces cause displacement of the tooth during chairside manipulation of wires [11].

It has already been confirmed by other researchers that self-ligating brackets comprise lesser frictional resistance to sliding which lessens the magnitude of a force requisite for movement. Moreover, reduced forces are less painful. Conversely, pain resulted from force magnitudes is influenced by the arch wires used in treatment $[14,15]$. Three studies already reported that lesser pain in patients when different self-ligating brackets were used $[5,16,17]$. On the other hand, one study found no significant difference between selfligating and conventional brackets in terms of pain, but the author concluded in his review article that evidence is more supportive for the concept of lower pain with self- ligating brackets [3,18].

The duration of orthodontic treatment and the rate of tooth movement has always been debated. Canine retraction in a split-mouth study was investigated for self-ligating and conventional brackets showed no significant differences in one study. However, the sample size was not sufficient to conclude the result [19]. Other authors followed the same research with a large number of samples and also found an insignificant result [20]. Conversely, some studies suggested that self-ligating brackets exhibited better results with fewer and quicker visits [5,21,22]. However, two systematic reviews do not support the concept of less treatment duration with self-ligating brackets due to the insufficient data $[17,18]$.

Self-ligating brackets are ligature-less brackets and consume innate mechanism to release and secure the arch wires. Regardless of the inbuilt design, these brackets are supported to have stout and secured ligation system, which reduces chairside time [23]. Moreover, self-ligating brackets are claimed to be more hygienic, improve plaque control and comfort for the patients [24]. Though, most of these claims are still controversial and need detailed researches [25].

In addition, the results add significant data regarding the experience of pain with traditional or selfligating fixed appliances. Patients treated with self-ligating brackets recorded significantly lower NRS scores than those treated with conventional brackets, suggesting that lower friction may have an effect on tooth movement and result in less pain. The orthodontic retraction of the anterior teeth has a pleasant effect on facial profiles [26]. The en-masse retraction with the help of power chain showed significantly faster closer of extraction spaces using passive self-ligating brackets when compared to conventional brackets [27]. Several studies have demonstrated a significant decrease in friction of self-ligating brackets compared with conventional brackets [10,27].

\section{Conclusion}

As pain during orthodontic treatment is mostly associated with the level of compression of the periodontal ligament, it may be hypothesized that lower frictional forces generate less compression of the periodontal ligament and blood vessels and so alter the type of pain experienced 


\section{Acknowledgment}

USM/ Vice-Chancellor Award 2016.

\section{Authors' Contributions}

\begin{tabular}{|c|c|c|}
\hline IQ & (D) $0000-0002-5179-7780$ & $\begin{array}{l}\text { Conceptualization, Methodology, Investigation, Formal Analysis, Writing - } \\
\text { Original Draft Preparation and Writing - Review and Editing. }\end{array}$ \\
\hline AGK & (iD) $0000-0002-9914-3524$ & Conceptualization, Methodology, Investigation and Formal Analysis. \\
\hline FMA & (D) $0000-0002-3248-5677$ & Conceptualization, Methodology, Investigation and Formal Analysis. \\
\hline MK & (iD) $0000-0002-0581-3102$ & Conceptualization and Methodology. \\
\hline SAN & (D) $0000-0001-7730-4481$ & $\begin{array}{l}\text { Conceptualization, Methodology, Writing - Original Draft Preparation and } \\
\text { Writing - Review and Editing. }\end{array}$ \\
\hline FS & (iD) $0000-0002-8899-2299$ & $\begin{array}{l}\text { Conceptualization, Methodology, Writing - Original Draft Preparation and } \\
\text { Writing - Review and Editing. }\end{array}$ \\
\hline MKA & (D) $0000-0001-7131-1752$ & $\begin{array}{l}\text { Conceptualization, Methodology, Writing - Original Draft Preparation and } \\
\text { Writing - Review and Editing. }\end{array}$ \\
\hline
\end{tabular}

\section{Financial Support}

None.

\section{Conflict of Interest}

The authors declare no conflicts of interest.

\section{References}

[1] Westley H. Risks and complications in orthodontic treatment. Dent Nurs 2010; 6(6):318-21. https://doi.org/10.12968/denn.2010.6.6.48172

[2] Proffit WR, Fields Jr HW, Sarver DM. Contemporary Orthodontics. 5th. ed. London: Elsevier Health Sciences, 2012.

[3] Fleming P, Dibiase A, Sarri G, Lee R. Pain experience during initial alignment with a self-ligating and a conventional fixed orthodontic appliance system: a randomized controlled clinical trial. Angle Orthod 2009; 79(1):46-50. https://doi.org/10.2319/121007-579.1

[4] Meling TR, Ødegaard J, Holthe K, Segner D. The effect of friction on the bending stiffness of orthodontic beams: a theoretical and in vitro study. Am J Orthod Dentofacial Orthop 1997; $112(1): 41-9$. https://doi.org/10.1016/s0889-5406(97)70272-5

[5] Tagawa D. The damon system vs. conventional appliances: a comparative study. Clin Impress. 2006;15(1):4-9.

[6] Kafle D, Rajbhandari A. Anticipated pain and pain experience among orthodontic patients: is there any difference? Kath Uni Med J 2013; 10(2):71-3. https://doi.org/10.3126/kumj.v10i2.7348

[7] Krishnan V. Orthodontic pain: from causes to management - a review. Euro J Orthod 2007; 29(2):170-9. https://doi.org/10.1093/ejo/cjlo81

[8] Kluemper GT, Hiser DG, Rayens MK, Jay MJ. Efficacy of a wax containing benzocaine in the relief of oral mucosal pain caused by orthodontic appliances. Am J Orthod Dentofacial Orthop 2002; 122(4):359-65. https://doi.org/10.1067/mod.2002.126405

[9] Keim RG. Managing orthodontic pain. J Clin Orthod 2004; 38(12):641-2.

[10] Doshi-Mehta G, Bhad-Patil WA. Efficacy of low-intensity laser therapy in reducing treatment time and orthodontic pain: A clinical investigation. Am J Orthod Dentofacial Orthop 2012; 141(3):289-97. https://doi.org/10.1016/j.ajodo.2011.09.009

[11] Bertl MH, Onodera K, Celar AG. A prospective randomized split-mouth study on pain experience during chairside archwire manipulation in self-ligating and conventional brackets. Angle Orthod 2012; 83(2):292-7. https://doi.org/10.2319/042312-338.1

[12] Türkkahraman H, Sayın M, Bozkurt FY, Yetkin Z, Kaya S, Önal S. Archwire ligation techniques, microbial colonization, and periodontal status in orthodontically treated patients. Angle Orthod 2005; 75(2):231-6.

[13] Burstone CJ. The Biomechanics of Tooth Movement. in: BS Kraus, RA Riedel (Eds.) Vistas in Orthodontics. Philadelphia: Lea \& Febiger, 1962. pp. 197-213. 
[14] Heo W, Baek SH. Friction properties according to vertical and horizontal tooth displacement and bracket type during initial leveling and alignment. Angle Orthod 2011; 81(4):653-61. https://doi.org/10.2319/072310-431.1

[15] Matarese G, Nucera R, Militi A, Mazza M, Portelli M, Festa F, et al. Evaluation of frictional forces during dental alignment: an experimental model with 3 nonleveled brackets. Am J Orthod Dentofacial Orthop 2008; 133(5):708-15. https://doi.org/10.1016/j.ajodo.2006.06.021

[16] Pringle AM, Petrie A, Cunningham SJ, McKnight M. Prospective randomized clinical trial to compare pain levels associated with 2 orthodontic fixed bracket systems. Am J Orthod Dentofacial Orthop 2009; 136(2):160-7. https://doi.org/10.1016/j.ajodo.2007.08.032

[17] Scott P, DiBiase AT, Sherriff M, Cobourne MT. Alignment efficiency of damon3 self-ligating and conventional orthodontic bracket systems: A randomized clinical trial. Am J Orthod Dentofacial Orthop 2008; 134(4):470.e1-8. https://doi.org/10.1016/j.ajodo.2008.04.018.

[18] Fleming PS, Johal A. Self-ligating brackets in orthodontics. a systematic review. Angle Orthod 2010; 80(3):575-84. https://doi.org/10.2319/081009-454.1.

[19] Miles PG. Self-ligating vs conventional twin brackets during en-masse space closure with sliding mechanics. Am J Orthod Dentofacial Orthop 2007; 132(2):223-5. https://doi.org/10.1016/j.ajodo.2007.04.028

[20] Mezomo M, de Lima ES, de Menezes LM, Weissheimer A, Allgayer S. Maxillary canine retraction with self-ligating and conventional brackets: a randomized clinical trial. Angle Orthod 2011; 81(2):292-7. https://doi.org/10.2319/062510-348.1

[21] Damon D. The rationale, evolution and clinical application of the self-ligating bracket. Clin Orthod Res 1998; 1(1):5261. https://doi.org/10.1111/ocr.1998.1.1.52

[22] Eberting JJ, Straja SR, Tuncay OC. Treatment time, outcome, and patient satisfaction comparisons of damon and conventional brackets. Clin Orthod Res 2001; 4(4):228-34. https://doi.org/10.1034/j.1600-0544.2001.40407.x

[23] Harradine NW. Self-ligating brackets: where are we now? J Orthod 2003; 30(3):262-73. https://doi.org/10.1093/ortho/30.3.262

[24] Rinchuse DJ, Miles PG. Self-ligating brackets: present and future. Clin Orthod Res 2007; 132(2):216-22. https://doi.org/10.1016/j.ajodo.2006.06.018

[25] Swartz ML. Fact or friction: the clinical relevance of in vitro steady-state friction studies. J Clin Orthod. 2007; 41(8):427-32.

[26] Permata DW, Purwanegara MK, Purbiati M. Soft tissue changes after orthodontic anterior retraction in adult indonesian patients with the dolichofacial type. J Int Dent Med Res 2018; 11(2):414-9.

[27] Soegiharto BM. The comparison of space closure rate between conventional and passive self-ligating system using elastomeric chain in maxilla. J Int Dent Med Res 2016; 9:356-61. 